\title{
Scholarly Nests
}

\section{Delvon T. Mattingly ${ }^{1}$ (B)}

Received: 25 November 2019 / Accepted: 12 February 2020 / Published online: 2 March 2020

(C) Academic Psychiatry 2020

Brittle moods of which form storms

find calm in scholarly nests,

burgeoning in resources

that are available to fledglings.

My desire to mend blemishes

the eyes cannot see

incites censure among inner voices

and fear in my decision to seek help,

in worry that pale helping hands

may squeeze out my remaining life.

These voices have not once

been at such crossroads of options,

for exclusion to access transforms

into a short trudge to an office,

each trip breeding uncertainty

as the nests fail to assuage pain

that feels unfamiliar.

Poet's Statement: The overall theme of this work reflects the phenomenon in which mental health resources at academic institutions feel less accommodating to underrepresented minority students. This is due to the interplay of several factors including cultural barriers and stigma. While many universities have initiatives that promote diversity and inclusion, resources created to improve mental health lack minority representation or professionals with culturally sensitive therapy models. As someone who battles depression and has sought therapy in the past, the purpose of this poem is to shed more light on these issues that exist in many academic institutions across the USA.

Delvon T. Mattingly

delvon@umich.edu

1 University of Michigan School of Public Health, Ann Arbor, MI, USA
The piece opens up with an allegory of inclusiveness. The poetic imagery of nests represents settings in which students receive mental health services in academia. Nests are primarily used by birds to care for their young, and each type of nest is built to accommodate specific birds. However, the narrator is explicit about the idea that every fledging, or student, has access to these resources. The poem transitions to the narrator's inner conflicts of community shame in seeking mental health care; for example, psychiatric illness or disability is associated with weakness or ostracization in some communities. These realities are difficult to confront despite continued attempts by academic institutions, and their representatives, to destigmatize receiving mental health care. Moreover, the narrator alludes to a general distrust of medical professionals among minorities. The final stanza completes the poem by showing that the narrator is one of the firsts in their community with a seemingly burdenless ability to seek counseling through their academic institution. However, the narrator's doubts come to light after discovering that they remain somewhat helpless following each session. The poem ends ambiguously as the narrator's uncertainty can originate from many different factors. These factors include, but are not limited to, the lack of cultural awareness and relatability shared between clinicians and clients, the inability by clinicians to reframe their therapy models to better suit underrepresented minority clients, and various forms of discrimination manifested by clinicians.

\section{Compliance with Ethical Standards}

Ethical Considerations N/A

Conflict of Interest The author states that there is no conflict of interest.

Publisher's Note Springer Nature remains neutral with regard to jurisdictional claims in published maps and institutional affiliations. 